\title{
Do happy catalyst supports work better? Surface coating of silica and titania supports with (poly)dopamine and their application in hydrotreating
}

\author{
Rajesh Munirathinam, Dorothée Laurenti, Denis Uzio*, Gerhard D. Pirngruber* \\ IFP Energies Nouvelles (IFPEN) - Lyon, Rond-point de l'échangeur de Solaize, BP 3, 69360 \\ Solaize, France \\ *Corresponding authors: Tel.: +33 437702243 (D. Uzio) / +33 437702733 (G. D. Pirngruber). \\ E-mail address: denis.uzio@ifpen.fr (D. Uzio) / gerhard.pirngruber@ifpen.fr (G. D. Pirngruber).
}

\begin{abstract}
In order to meet the demand for cleaner fuels, it is necessary to develop high performing hydrotreating catalysts. Although organic additives are often used to improve the performances of hydrotreating catalysts, bio-polymer additives have not yet been thoroughly investigated. We recently showed that dopamine, a neurotransmitter molecule, which is also frequently found in adhesive bio-polymers, efficiently coats the surface of an alumina carrier material and modifies the interaction with active components of hydrotreating catalysts, i.e. cobalt and molybdenum. The catalytic performance of the CoMoS/ $/ \mathrm{Al}_{2} \mathrm{O}_{3}$ catalysts could, thus, be improved. In the present paper we extend the strategy to other carrier materials (silica and titania). The catalysts prepared on (poly)dopamine (Pdop) coated silica showed enhanced activity for the hydrogenation of toluene reaction and the selective HDS of FCC gasoline model feed. Pdop coating lowers the $\mathrm{MoS}_{2}$ nanocrystallites' stacking on silica, thereby improving the accessibility of active edge sites. The origin of this increase in catalytic activity may be found in the higher capacity of Pdop's functional groups to interact with metallic precursors leading to a better dispersion of the active phase. On the contrary, when the interaction between the dopamine and the support is too strong (as observed for $\mathrm{TiO}_{2}$ ), the functional groups of Pdop are not available for interaction with Co and Mo species, resulting in decreased catalytic activity.
\end{abstract}

\section{Keywords:}

Carbon coating, Hydrodesulfurization, Hydrotreating reactions, Polydopamine, Silica, Titania

\section{Highlights:}

- $\mathrm{SiO}_{2}$ and $\mathrm{TiO}_{2}$ surfaces were successfully coated by polydopamine (Pdop).

- CoMos catalysts supported on $\mathrm{Pdop} / \mathrm{SiO}_{2}$ showed better dispersion and two-fold increase in catalytic activity than their counterparts on bare $\mathrm{SiO}_{2}$.

- Opposite effect was observed CoMoS catalysts supported on $\mathrm{Pdop} / \mathrm{TiO}_{2}$.

- Nature of interaction between the support and Pdop functional groups determines the final outcome of the catalyst dispersion and their activity. 


\section{Introduction}

Environmental regulations are continuously strengthened to limit the emission of pollutants from fossil fuels combustion [1]. In addition, natural resources supplying the metal sources for hydrotreating catalysts are limited whereas liquid fuel demand is expected to grow by $48 \%$ between 2012 and 2040 (source: International Energy Outlook 2016). These constraints drive the need to develop highly active and efficient hydrotreating catalysts. Industrial hydrotreating catalysts contain Mo (and/or W) as the active metal usually promoted by $\mathrm{Co}$ (and/or $\mathrm{Ni}$ ) and supported on $\mathrm{Al}_{2} \mathrm{O}_{3}, \mathrm{SiO}_{2}$ or $\mathrm{TiO}_{2}$ [2]. In order to improve their performances, different strategies have been explored such as the use of polyoxometalates [3], or different kinds of organic additives, namely, organic chelating [4-6] or non-chelating (e.g. glycols) agents [7,8].

The support effect is an important field of investigation in hydrotreating catalysis. Indeed, metal-support interactions are known to influence various characteristics of the active phase such as its morphology, slabs orientation, or electronic properties [9-12]. Acid or basic sites on the support surface can also intervene directly in the catalytic cycle and enhance the formation of the desired products, but in many cases also promote the formation of undesired side products [13]. Silica is an interesting option when acid catalyzed reactions (olefin polymerization, coke formation, etc.) are detrimental, or when low metal support interactions are required to limit the formation of refractory phases $[14,15]$. However, silica-supported catalysts generally show lower activity than alumina counterparts due to the relatively inert surface making it difficult to form the highly dispersed and promoted sulfide phase, especially at high loadings. In order to circumvent such limitations, coating the surface of silica with a polymer that contains different functional groups able to interact with metallic precursors is one of the suitable option to improve surface reactivity and dispersion [16].

Titania is also a very interesting support material. Non-promoted $\mathrm{MoS}_{2} / \mathrm{TiO}_{2}$ catalysts are four to five times more active than their alumina counterparts [17]. The high activity was explained either by electronic effects, or by the epitaxial relationship between anatase and $\mathrm{MoS}_{2}$, which leads to edge-bonded slabs that mainly expose M-edges. Yet, the promotion effect of $\mathrm{Co}$ on titania supported $\mathrm{MoS}_{2}$ is weaker than the one observed on $\gamma-\mathrm{Al}_{2} \mathrm{O}_{3}$ for instance, because only a small fraction of $\mathrm{Co}$ is incorporated into the mixed CoMoS phase [9].

In a recent study from our group, we have successfully modified the surface properties of alumina carriers, by coating with the bio-molecule dopamine. Under soft conditions, a polydopamine-coated alumina was obtained [18]. The choice of dopamine monomer is (bio)inspired from the properties of mussel adhesive proteins, on the basis of the strong interfacial binding property of embedded catechol groups [19]. Dopamine polymerizes under mild basic reactions conditions and invariably coat almost all kinds of materials such as metals, metal oxides, polymers, etc [20]. In addition, the chemical structure of polydopamine (Pdop) includes various functional groups such as catechol, quinone, amine and imine that are useful to bind many transition metal ions [21,22]. In the case of $\mathrm{Al}_{2} \mathrm{O}_{3}$, the Pdop coating of the surface prevented the direct interaction of cobalt and molybdenum species with the alumina surface (which leads to the formation of refractory species), while providing a higher number of binding sites for molybdenum precursors, leading in fine to an improved dispersion of the $\mathrm{MoS}_{2}$ slabs, in particular at high surface densities of molybdenum. The combination of both effects led to an 
improved activity of the CoMoS/Pdop $/ \mathrm{Al}_{2} \mathrm{O}_{3}$ in the hydrogenation of toluene and also in the hydrotreating of gasoil.

In contrast to alumina, silica has a fairly weak interaction with molybdenum species. The fact that the Pdop coating provides binding sites for molybdenum is therefore a particularly interesting strategy to improve the dispersion of $\mathrm{MoS}_{2}$ slabs on the silica surface. In the case of titania, the effect of the Pdop coating is difficult to predict, because of the very specific interaction between $\mathrm{MoS}_{2}$ slabs and the titania surface.

In the present work, we show how $\mathrm{SiO}_{2}$ and $\mathrm{TiO}_{2}$ carriers can be coated by Pdop. The coated supports were characterized in detail and then used for preparation of hydrotreating catalysts, via classical incipient wetness impregnation of molybdenum and cobalt species. The performance of the sulfide catalysts in toluene hydrogenation and selective hydrodesulfurization (HDS) of 3-methylthiophene was assessed and discussed in relation with characterization results.

\section{Experimental Section}

\subsection{Materials}

All the chemicals were purchased from Sigma Aldrich and used as received unless specified. Silica and titania (anatase) supports were provided by Saint-Gobain and Huntsman, respectively. The shaping of the titania supports was done in-house.

\subsection{Support modification}

$\mathrm{SiO}_{2}$ support (1.6 mm diameter cylindrical extrudates, $\mathrm{V}_{\mathrm{p}}=1.10 \mathrm{~cm}^{3} \mathrm{~g}^{-1}, \mathrm{~S}_{\mathrm{BET}}=233 \mathrm{~m}^{2} \mathrm{~g}^{-1}$, $\mathrm{d}_{\mathrm{p}}=12.9 \mathrm{~nm}$ ) was coated with Pdop by incipient wetness impregnation. The desired amount of dopamine-hydrochloride was dissolved in water and impregnated onto $\mathrm{SiO}_{2}$. Impregnation was followed by a maturation step in a water saturated atmosphere, for overnight at room temperature. Then, a drying step was performed for $20 \mathrm{~h}$ at $90^{\circ} \mathrm{C}$ which yielded Pdop coated silica $\left(\mathrm{Pdop} / \mathrm{SiO}_{2}\right)$. The drying step helps in polymerizing dopamine [23] partially, as observed by the change in color of the support from white to brown. A similar approach was used to coat titania (1.6 mm diameter trilobe extrudates, $V_{p}=0.63 \mathrm{~cm}^{3} \mathrm{~g}^{-1}, \mathrm{~S}_{\mathrm{BET}}=173 \mathrm{~m}^{2} \mathrm{~g}^{-1}, \mathrm{~d}_{\mathrm{p}}=17.2 \mathrm{~nm}$ ) with Pdop to obtain Pdop/TiO . Pdop coated $\mathrm{TiO}_{2}$ is an orange solid. $\mathrm{Pdop} / \mathrm{SiO}$ and $\mathrm{Pdop} / \mathrm{TiO}_{2}$ supports used for the catalyst preparation contain Pdop loading of $13.8 \mathrm{wt} \%$ on $\mathrm{SiO}_{2}$ and 6.4 $w t \%$ on $\mathrm{TiO}_{2}$.

\subsection{Catalyst preparation}

Series of $\mathrm{CoMo} / \mathrm{Pdop} / \mathrm{SiO}_{2}$ and $\mathrm{CoMo} / \mathrm{SiO}_{2}$ catalysts with 10 or 20 wt\% loading of $\mathrm{MoO}_{3}$ (with respect to the oxide form of the catalysts) and $\mathrm{Co} /(\mathrm{Co}+\mathrm{Mo})$ molar ratio of 0.3 were prepared by incipient wetness impregnation method and labelled as $10(20) \% \mathrm{CoMo} / \mathrm{Pdop} / \mathrm{SiO}_{2}$ and $10(20) \% \mathrm{CoMo} / \mathrm{SiO}_{2}$. Phosphomolybdic acid $\left(\mathrm{H}_{3} \mathrm{PMo}_{12} \mathrm{O}_{40} \cdot 30 \mathrm{H}_{2} \mathrm{O}\right)$ and $\mathrm{Co}\left(\mathrm{NO}_{3}\right)_{2} \cdot 6 \mathrm{H}_{2} \mathrm{O}$ were used as precursors dissolved in ethanol. The solution containing the metal precursors was impregnated and left for maturation in an ethanol saturated atmosphere, at room temperature 
overnight. Then, the catalysts were dried in a rotary evaporator under reduced pressure $(\sim 50$ mbar) for $2 \mathrm{~h}$ at $40^{\circ} \mathrm{C}$ which yielded $\mathrm{CoMo} / \mathrm{Pdop} / \mathrm{SiO}_{2}$ or $\mathrm{CoMo} / \mathrm{SiO}_{2} .10 \% \mathrm{CoMo} / \mathrm{Pdop} / \mathrm{TiO}_{2}$ and $10 \% \mathrm{CoMo} / \mathrm{TiO}_{2}$ catalysts were also prepared using the same method described above. The catalysts were sulfided in gas-phase at atmospheric pressure before characterization. For sulfidation, catalysts were introduced in a glass reactor and heated from room temperature to $350^{\circ} \mathrm{C}$ with a ramp of $5^{\circ} \mathrm{C} \mathrm{min}^{-1}$ with a plateau of $2 \mathrm{~h}$, under a $15: 85 \mathrm{v} / \mathrm{v} \mathrm{H}_{2} \mathrm{~S} / \mathrm{H}_{2}$ flow of $1.8 \mathrm{~L} \mathrm{~g}^{-}$ ${ }_{\text {catalyst }} \mathrm{h}^{-1}$. At the end of the plateau, the reactor was cooled down to $50^{\circ} \mathrm{C}$ and the $\mathrm{H}_{2} \mathrm{~S} / \mathrm{H}_{2}$ mixture was replaced by argon and the reactor was flushed for $15 \mathrm{~min}$. Finally, the reactor was evacuated ( $\sim 1 \mathrm{mbar})$ and the cell was sealed. The sulfided catalysts are henceforth denoted as CoMoS/Pdop/( $\left.\mathrm{TiO}_{2}\right) \mathrm{SiO}_{2}$ and $\mathrm{CoMoS} /\left(\mathrm{TiO}_{2}\right) \mathrm{SiO}_{2}$.

\subsection{Catalysts characterization}

Fourier transform infrared spectroscopy (FTIR), thermogravimetric analysis (TGA), textural, elemental (XRF and CHNS), in-situ XRD, electron probe microprobe analysis (EPMA), transmission electron microscopy (TEM), and X-ray photoelectron spectroscopy (XPS) analysis were performed as described before [18]. The results of elementary analysis are presented in Table 1. Targeted $\mathrm{MoO}_{3}$ loadings were based on the oxide form of the bare support.

\section{Table 1}

\%wt of (i) Mo and Co in the catalyst before sulfidation from XRF analysis, and (ii) $\mathrm{C}$ and $\mathrm{S}$ in the sulfide catalysts from CHNS analysis.

\begin{tabular}{|c|c|c|c|c|c|c|}
\hline Catalysts & $\begin{array}{c}\text { Targeted } \\
\mathrm{MoO}_{3} \\
\text { wt\% }\end{array}$ & $\begin{array}{c}\mathrm{Mo} \\
\text { wt\% }\end{array}$ & $\begin{array}{c}\text { Actual } \\
\mathrm{MoO}_{3} \text { wt }^{a}\end{array}$ & $\begin{array}{c}\mathrm{Co} \\
\text { wt\% }\end{array}$ & $\begin{array}{c}\mathrm{S} \\
\text { wt\% }\end{array}$ & $\begin{array}{c}\mathrm{C} \\
\text { wt\% }\end{array}$ \\
\hline $10 \% \mathrm{CoMo} / \mathrm{SiO}_{2}$ & 10 & 5.7 & 8.5 & 1.5 & 5.9 & n.d. \\
\hline $10 \% \mathrm{CoMo} / \mathrm{Pdop} / \mathrm{SiO}_{2}$ & 10 & $6.0^{*}$ & $9.0^{*}$ & $1.6^{*}$ & 5.5 & 5.3 \\
\hline $20 \% \mathrm{CoMo} / \mathrm{SiO}_{2}$ & 20 & 10.6 & 15.8 & 2.8 & 11.0 & n.d. \\
\hline $20 \% \mathrm{CoMo} / \mathrm{Pdop} / \mathrm{SiO}_{2}$ & 20 & $11.9^{*}$ & $17.8^{*}$ & $3.1^{*}$ & 10.4 & 2.4 \\
\hline $10 \% \mathrm{CoMo} / \mathrm{TiO}_{2}$ & 10 & 5.4 & 8.1 & 1.8 & 7.2 & n.d. \\
\hline $10 \% \mathrm{CoMo} / \mathrm{Pdop} / \mathrm{TiO}_{2}$ & 10 & 4.8 & 7.1 & 1.5 & 6.4 & 0.9 \\
\hline
\end{tabular}

${ }^{*} \mathrm{MoO}_{3}$ and $\mathrm{CoO}$ contents of these catalysts are from the sulfided catalysts. n.d. not detected. ${ }^{\mathrm{a}} \mathrm{MoO}_{3} \mathrm{wt} \%$ was calculated from the measured Mo wt\% from XRF.

\subsubsection{Solid state UV analysis}

A double-beam Lambda 35 UV-Vis spectrophotometer from Perkin-Elmer equipped with an integrating Lab sphere RSA-PE-20 recording the spectra over 200-1000 nm range was used with a data interval of $2 \mathrm{~nm}$. The spectra were recorded in reflectance mode. The parameters used were $4 \mathrm{~nm} \mathrm{~s}^{-1}$ as scan speed and $2 \mathrm{~nm}$ as slit width. Spectralon was used as a reference. Samples were prepared by mixing $10 \mathrm{mg}$ of pure sample with $190 \mathrm{mg}$ of $\mathrm{BaSO}_{4}$. 


\subsection{Catalytic tests}

\subsubsection{Hydrogenation of Toluene}

The sulfided catalysts were evaluated in toluene hydrogenation (HYD) reaction in a fixed bed unit reactor Flowrence (Avantium), containing 16 parallel reactors, filled with $450 \mu \mathrm{L} \mu \mathrm{L}$ of the catalyst, as described before [18]. Briefly, the feed was composed of dimethyldisulfide (DMDS, $5.8 w t \%)$ and toluene (20 wt\%) in cyclohexane (74.2 wt\%). The hydrogen to feed ratio $\left(\mathrm{H}_{2} / \mathrm{HC}\right)$ was $450 \mathrm{NL} / \mathrm{L}$ during the test and the in-situ presulfidation step, which was performed at $350^{\circ} \mathrm{C}$ with a liquid hourly space velocity (LHSV) of $4 \mathrm{~h}^{-1}$ and a total pressure of 60 bar for $2 \mathrm{~h}$. After this presulfidation step, LHSV was reduced to $2 \mathrm{~h}^{-1}$. The first order rate constant $\left(k, \mathrm{~h}^{-1}\right)$ was calculated by the following expression (1):

$$
k=L H S V * \ln \left(\frac{1}{1-x}\right), L H S V=\frac{\text { flow rate of the feed }}{\text { volume of the catalytic bed }}, k^{\prime}=\frac{k}{\text { mol(Mo) }}(1)
$$

$x$ is the percentage conversion of toluene (HYD) in the feed. LHSV is the liquid hourly space velocity $\left(\mathrm{h}^{-1}\right) \cdot k^{\prime}\left(\mathrm{cm}^{3} \mathrm{~mol}_{\mathrm{Mo}}^{-1} \mathrm{~h}^{-1}\right)$ is obtained by normalizing $k$ with the number of moles of Mo present in the catalyst loaded in the test.

\subsubsection{HDS of 3-methylthiophene (3-MT) and hydrogenation (HYD) of 2,3-dimethyl-2- butene (2,3-DM2B): Model FCC gasoline feed test}

The catalysts were also evaluated in selective HDS of model FCC gasoline test in the Flowrence unit from Avantium, using circa $300 \mu \mathrm{L}$ of catalyst in each fixed bed reactor. The presulfidation of the catalysts was performed using a feed composed of DMDS (4 wt\%) in $n$ heptane (96 wt\%), at a LHSV of $3 \mathrm{~h}^{-1}$, at a total pressure of 15 bar, for $2 \mathrm{~h}$, and with a hydrogen to feed ratio $\left(\mathrm{H}_{2} / \mathrm{HC}\right)$ of $300 \mathrm{NL} / \mathrm{L}$. The temperature was increased from room temperature to $350^{\circ} \mathrm{C}$ with a ramp of $2^{\circ} \mathrm{C} \mathrm{min}^{-1}$. After the sulfidation step, the temperature was decreased to $190^{\circ} \mathrm{C}$. The catalytic test was carried out with a feed composed of 2,3-DM2B (10 wt\%), and 3MT (0.3 wt\%) dissolved in n-heptane (89.7 wt\%), at a LHSV of $6 \mathrm{~h}^{-1}$, with total pressure of 15 bar, and the hydrogen to feed ratio $\left(\mathrm{H}_{2} / \mathrm{HC}\right)$ of $300 \mathrm{NL} / \mathrm{L}$. Later, the temperature was increased from 190 to $220^{\circ} \mathrm{C}$ with an increment of $10^{\circ} \mathrm{C}$. The liquid products of the reaction were analyzed by gas chromatography using a DB1 column. The first order rate constant $\left(k, \mathrm{~h}^{-1}\right)$ was calculated by the following expression (2):

$$
k(H D S \text { or } H Y D)=L H S V * \ln \left(\frac{1}{1-X_{H D S}(H Y D)}\right)
$$

$x$ is the conversion of 3-MT (HDS) or the hydrogenation of 2,3-DM2B (HYD). As previously described, $k^{\prime}\left(\mathrm{cm}^{3} \mathrm{~mol}_{\mathrm{Mo}}{ }^{-1} \mathrm{~h}^{-1}\right)$ is obtained by normalizing $k$ with the number of moles of loaded Mo. 


\section{Results and Discussion}

\subsection{Coating of silica support with Pdop}

\subsubsection{Fourier Transform Infrared Spectroscopy (FTIR)}

FTIR spectra of the $\mathrm{SiO}_{2}$ and $\mathrm{Pdop} / \mathrm{SiO}_{2}$ supports prepared by impregnating the carrier with 6.4 or 13.8 wt\% of dopamine-hydrochloride are shown in Fig. 1. The sharp peak at 3747 $\mathrm{cm}^{-1}$ corresponds to stretching vibrations of the isolated surface silanol (SiOH) groups on silica support [24]. This signal drops when Pdop loading increases, and at $13.8 \mathrm{wt} \%$ of Pdop, the majority of the free $\mathrm{OH}$ groups on $\mathrm{SiO}_{2}$ has disappeared (Fig. 1C). Infrared bands between 1650 and $1400 \mathrm{~cm}^{-1}$ represent the vibration modes of aromatic rings indicative of the presence of single or condensed aromatic rings [25]. The band corresponding to ammonium ion $\left(\sim 1612 \mathrm{~cm}^{-1}\right)$ stretching from dopamine-hydrochloride salt (Fig. 1d) has almost disappeared on $\mathrm{Pdop} / \mathrm{SiO}_{2}$ (Fig. $1 \mathrm{~b}$ and 1c), indicating the transformation of the salt form of dopamine. Further, drying conditions $\left(90^{\circ} \mathrm{C}\right.$ for $\left.20 \mathrm{~h}\right)$ helped to polymerize dopamine at least partially [23], as witnessed from the transformation of color from white to brown.

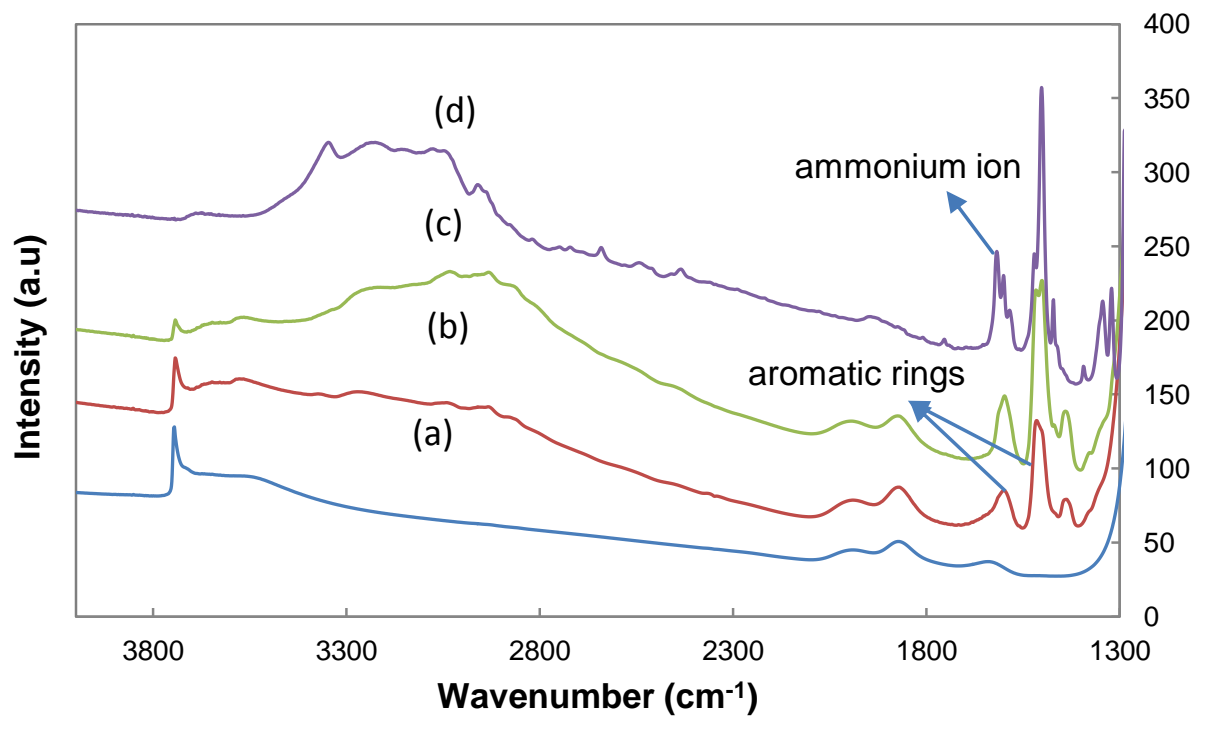

Fig. 1. FTIR spectra of (a) $\mathrm{SiO}_{2}$, (b) $6.4 \mathrm{wt} \% \mathrm{Pdop} / \mathrm{SiO}_{2}$, (c) $13.8 \mathrm{wt} \% \mathrm{Pdop} / \mathrm{SiO}_{2}$, and (d) dopaminehydrochloride after activating the samples at $90^{\circ} \mathrm{C}$ for $2 \mathrm{~h}$.

\subsubsection{Thermogravimetric and Solid-state UV analysis}

The thermal degradation profiles of $6.4 \mathrm{wt} \% \mathrm{Pdop} / \mathrm{SiO}_{2}$ and $13.8 \mathrm{wt} \% \mathrm{Pdop} / \mathrm{SiO}_{2}$ are depicted in Fig. 2. The free dopamine-hydrochloride decomposes at about $330^{\circ} \mathrm{C}$ (Fig. S1), whereas 6.4 wt $\% \mathrm{Pdop} / \mathrm{SiO}_{2}$ and $13.8 \mathrm{wt} \% \mathrm{Pdop} / \mathrm{SiO}_{2}$ decomposes only partially at $330^{\circ} \mathrm{C}$. The partial decomposition at $330^{\circ} \mathrm{C}$ reveals the presence of free or unpolymerized dopamine. However, the decomposition behavior continues up to $700^{\circ} \mathrm{C}$. This is a clear indication of the presence of polymerized/oligomerized dopamine, which undergoes thermal degradation at temperatures higher than $330^{\circ} \mathrm{C}$. Further, solid-state UV analysis of the $\mathrm{Pdop} / \mathrm{SiO}_{2}$ support (Fig. S2) showed 
an absorbance band at about $280 \mathrm{~nm}$ corresponding to catechol groups of dopamine [19]. In addition, an increase in absorbance in the region of $400-800 \mathrm{~nm}$ which is characteristic for the polymerization of dopamine, arising from different functional groups in Pdop was also observed [26].

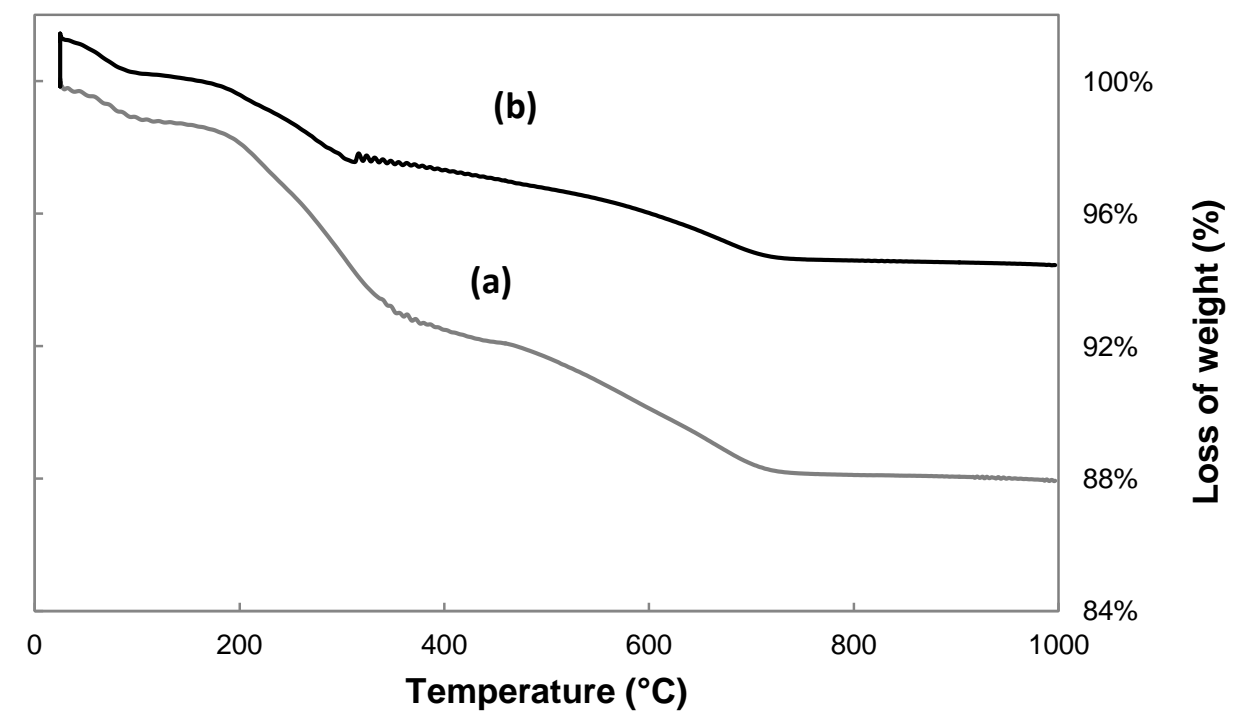

Fig. 2. Thermogravimetric analysis of (a) $6.4 \mathrm{wt} \% \mathrm{Pdop} / \mathrm{SiO}_{2}$, and (b) $13.8 \mathrm{wt} \% \mathrm{Pdop} / \mathrm{SiO}_{2}$ supports under $\mathrm{H}_{2}$ gas.

\subsubsection{Textural Analysis}

Nitrogen physisorption isotherms of $\mathrm{SiO}_{2}$ and $13.8 \mathrm{wt} \% \mathrm{Pdop} / \mathrm{SiO}_{2}$ supports are displayed in Fig. 3 (while usual BET surface area, pore volume and pore diameter are presented in Table $\mathrm{S1}$ ). The amount of adsorbed $\mathrm{N}_{2}$, normalized by the volume of the support [27] (obtained by multiplying the grain density with the weight of the carrier), does not change much when $\mathrm{SiO}_{2}$ is coated with 13.8 wt\%Pdop. This indicates that the dopamine coating does not reduce the pore volume. The shape of the isotherm is preserved, corresponding to type IV with $\mathrm{H} 1$ hysteresis before and after Pdop coating. The $\mathrm{N}_{2}$ isotherms suggests that we obtain a homogeneous coating of the surface, with no pore blocking effect. 


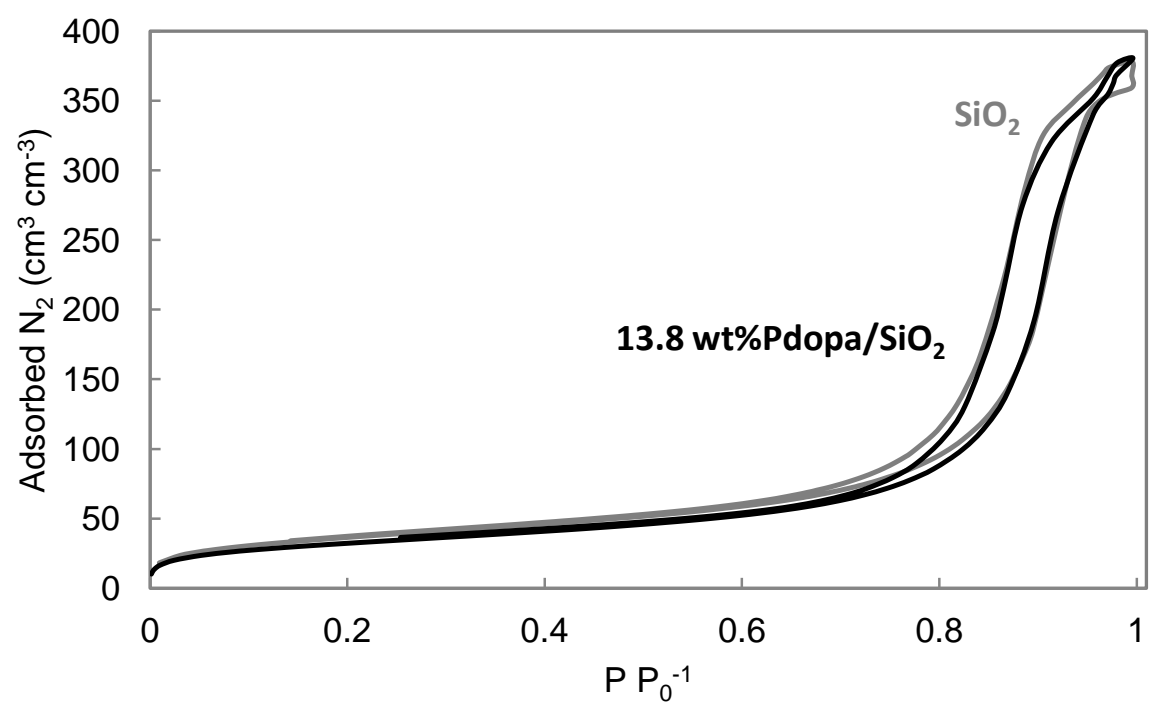

Fig. 3. $\mathrm{N}_{2}$ physisorption isotherms of $\mathrm{SiO}_{2}$ and $13.8 \mathrm{wt} \% \mathrm{Pdop} / \mathrm{SiO}_{2}$.

\subsection{CoMo supported on Pdop coated $\mathrm{SiO}_{2}$}

Both the pure and Pdop modified silica supports were impregnated with Mo and Co precursors using ethanol as the solvent as described in the experimental section. These catalysts were characterized by electron probe microanalysis to analyze the distribution of metal precursors within the extrudates. Distribution profiles of $\mathrm{Mo}, \mathrm{Co}$, and $\mathrm{P}$ in the cross section of $20 \% \mathrm{CoMo} / \mathrm{Pdop} / \mathrm{SiO}_{2}$ and $20 \% \mathrm{CoMo} / \mathrm{SiO}_{2}$ extrudates (Figs. S3-S4) in the oxide form of the catalysts showed that all the elements were homogeneously distributed. CHNS analysis results (Table 1) obtained on the $\mathrm{CoMoS} / 13.8 \mathrm{wt} \% \mathrm{Pdop} / \mathrm{SiO}_{2}$ catalysts showed that part of the carbon from Pdop (2.4 to $5.3 \mathrm{wt} \%$ ) is still present after sulfidation. $\mathrm{N}_{2}$ physisorption measurements on $20 \% \mathrm{CoMoS} / \mathrm{SiO}_{2}$ and $20 \% \mathrm{CoMoS} / \mathrm{Pdop} / \mathrm{SiO}_{2}$ sulfided catalysts displayed no significant difference for the adsorbed $\mathrm{N}_{2}$ volume (Figs. S5-6, See Table S1 for usual BET surface area, pore volume and pore diameter). It is important to note that despite of the presence of carbonaceous deposit after sulfidation, no pore blocking effect is detected in this study, in contrast to other studies on carbon coated supports reported in literature $[28,29]$.

\subsubsection{XRD analysis: In-situ sulfidation of CoMo catalysts supported on $\mathrm{SiO}_{2}$ and $\mathrm{Pdop} / \mathrm{SiO}_{2}$}

The sulfidation of $\mathrm{Mo}$ and $\mathrm{Co}$ supported on $\mathrm{SiO}_{2}$ and $\mathrm{Pdop} / \mathrm{SiO}_{2}$ (20 wt\% of targeted $\mathrm{MoO}_{3}$ loading) was analyzed in-situ by XRD, to follow the formation of $\mathrm{MoS}_{2}$ and $\mathrm{Co}_{9} \mathrm{~S}_{8}$ crystalline phases with the increase in temperature (Fig. 4). The formation of a crystalline $\mathrm{MoS}_{2}$ phase begins gradually on both supports above $200^{\circ} \mathrm{C}$. The increase in the intensity of the XRD reflections with temperature follows a similar trend for both supports, showing that the Pdop coating does not modify significantly the formation and growth of sulfide crystals, despite the complexation of Mo ions with catechol groups in Pdop (Figs. 4a and 4b) [30]. The height of the (002) peak calculated from Debye-Scherrer equation for crystalline $\mathrm{MoS}_{2}$ was used to get information about the stacking of $\mathrm{MoS}_{2}$ slabs on both supports [31]. The (002) peak of $\mathrm{MoS}_{2}$ is 

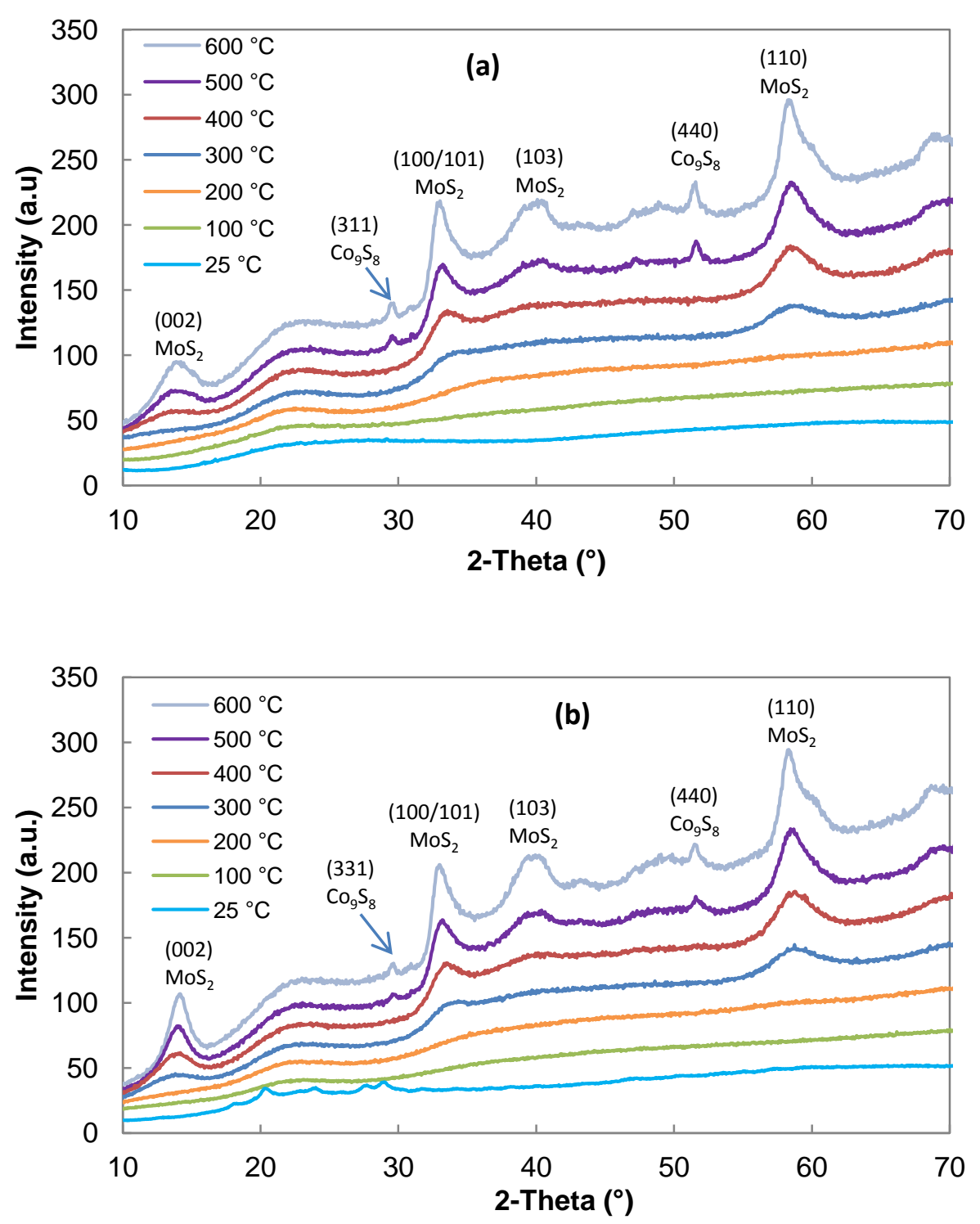

Fig. 4. XRD diffraction patterns of $\mathrm{MoS}_{2}$ and $\mathrm{Co}_{9} \mathrm{~S}_{8}$ phases on (a) $\mathrm{Pdop} / \mathrm{SiO}_{2}$ and (b) pure $\mathrm{SiO}_{2}$ obtained during in-situ sulfidation of the oxide catalysts.

broader and has a lower intensity on $\mathrm{Pdop} / \mathrm{SiO}_{2}$ (Fig. 4a) than on pure $\mathrm{SiO}_{2}$ (Fig. 4b), i.e. the $\mathrm{MoS}_{2}$ stacking on the Pdop/SiO 2 support is lower (Fig. S7, considering the Mo-Mo d-spacing of (002) crystal plane as $6.5 \AA$ for a single $\mathrm{MoS}_{2}$ layer [32]). Since stacking and dispersion are generally anti-correlated, $\mathrm{MoS}_{2}$ slabs are expected to be more dispersed on $\mathrm{Pdop} / \mathrm{SiO}_{2}$ than on pure $\mathrm{SiO}_{2}$. The formation of a crystalline $\mathrm{Co}_{9} \mathrm{~S}_{8}$ phase starts above $400^{\circ} \mathrm{C}$, and follows a similar trend for both pure $\mathrm{SiO}_{2}$ and $\mathrm{Pdop} / \mathrm{SiO}_{2}$. Above $400^{\circ} \mathrm{C}$, it is most likely that the Co ions present in the CoMoS starts to segregate from the sintering $\mathrm{MoS}_{2}$ slabs (which reduces the amount of Co that can decorate the edges of the slabs) and form the thermodynamically stable $\mathrm{Co}_{8} \mathrm{~S}_{9}$ phase. 


\subsubsection{TEM results}

The mean slab length and stacking of $\mathrm{MoS}_{2}$ nanocrystallites were determined from a statistical treatment of the TEM images. At both low and high Mo loadings, the stacking of the $\mathrm{MoS}_{2}$ slabs on $\mathrm{Pdop} / \mathrm{SiO}_{2}$ is significantly lower than on the corresponding bare $\mathrm{SiO}_{2}$ supports (See Figs. 5 and 6, and Table 2) in agreement with previous XRD results. The representative TEM micrographs reveal that, on pure $\mathrm{SiO}_{2}$, more aggregation/clusters of $\mathrm{MoS}_{2}$ slabs are observed (dark zones on representative images at low and high magnifications, Figs. 5a-b), compared to the Pdop-coated support (representative images, Figs. 5c-d). The impact of dopamine on the average slab length is less obvious since it slightly decreases at low Mo loading, but marginally increases at high Mo loading (Table 2).
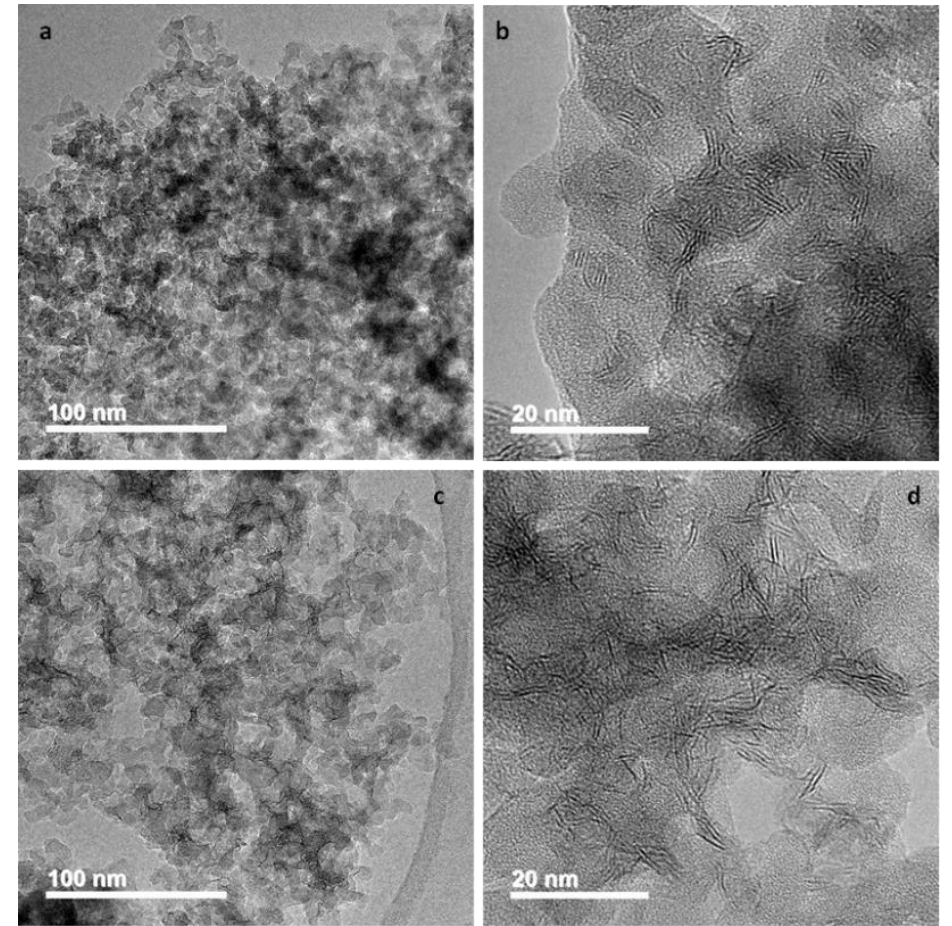

Fig. 5. TEM images of sulfided catalysts: a-b) $20 \% \mathrm{CoMoS} / \mathrm{SiO}_{2}$ and c-d) $20 \% \mathrm{CoMoS} / \mathrm{Pdop} / \mathrm{SiO}_{2}$.
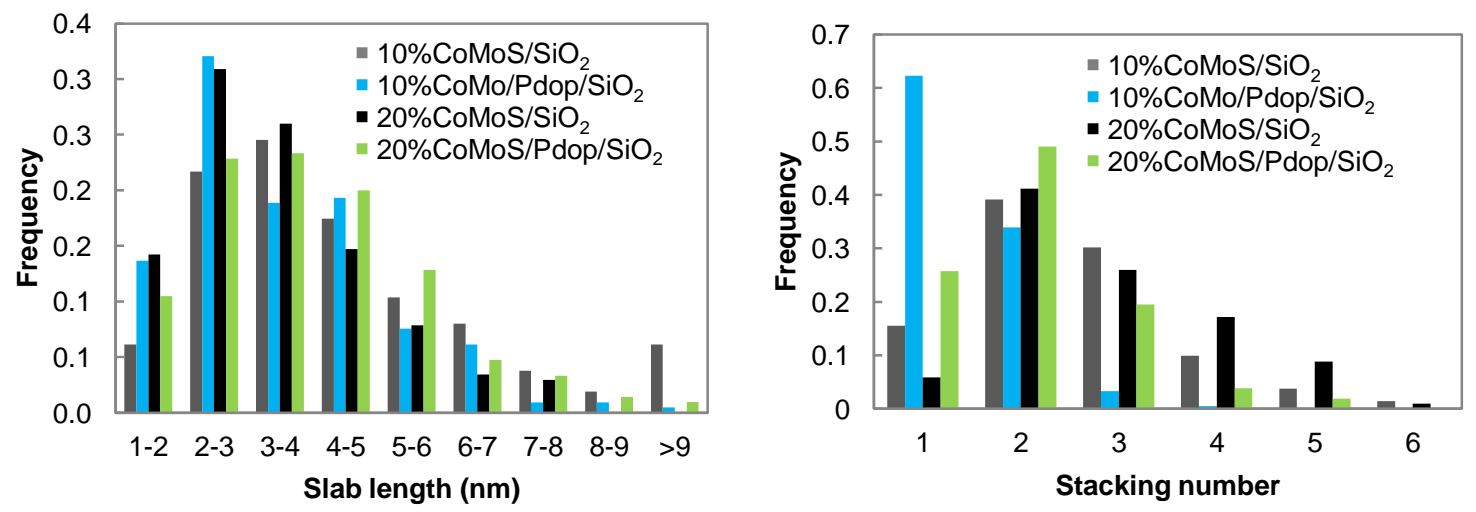

Fig. 6. Distributions of (a) slab length and (b) average stacking of the $\mathrm{MoS}_{2}$ particles in the CoMoS catalysts supported on $\mathrm{SiO}_{2}$ and $\mathrm{Pdop} / \mathrm{SiO}_{2}$ determined by TEM. 
Table 2

Average slab length and stacking CoMoS catalysts supported on $\mathrm{SiO}_{2}$ and $\mathrm{Pdop} / \mathrm{SiO}_{2}$ determined by TEM. The \pm interval indicates the width of the distribution and not the uncertainty of the average slab length and stacking.

\begin{tabular}{|c|c|c|}
\hline Catalysts & Slab length $(\mathbf{n m})$ & $\begin{array}{c}\text { Average } \\
\text { Stacking }\end{array}$ \\
\hline $10 \% \mathrm{CoMoS} / \mathrm{SiO}_{2}$ & $4.7 \pm 2.2$ & $2.5 \pm 1.1$ \\
\hline $10 \% \mathrm{CoMoS} / \mathrm{Pdop} / \mathrm{SiO}_{2}$ & $3.8 \pm 1.5$ & $1.4 \pm 0.6$ \\
\hline $20 \% \mathrm{CoMoS} / \mathrm{SiO}_{2}$ & $3.7 \pm 1.5$ & $2.9 \pm 1.1$ \\
\hline $20 \% \mathrm{CoMoS} / \mathrm{Pdop} / \mathrm{SiO}_{2}$ & $4.2 \pm 1.7$ & $2.1 \pm 0.9$ \\
\hline
\end{tabular}

\subsubsection{XPS results on CoMoS catalysts supported on $\mathrm{SiO}_{2}$ and $\mathrm{Pdop} / \mathrm{SiO}_{2}$}

The binding energies of Mo and Co ions in the sulfided (CoMoS) catalysts with/without Pdop were evaluated by XPS. In the case of Mo, the XPS spectra allow distinguishing $\mathrm{MoS}_{2}$, $\mathrm{MoO}_{3}$ and a species with an intermediate binding energy, a Mo-oxysulfide. Results from XPS (Table 3) do not show any observable difference in the degree of sulfidation of Mo ions for all the catalysts (both at low and high Mo loadings). However, at $10 \% \mathrm{MoO}_{3}$ loading, the amount of $\mathrm{Co}_{9} \mathrm{~S}_{8}$ phase is much lower on $\mathrm{Pdop} / \mathrm{SiO}_{2}$ when compared to that on pure $\mathrm{SiO}_{2}$, consequently, increasing the decoration ratio of $\mathrm{MoS}_{2}$ slabs by Co, i.e. the CoMoS phase $(+57 \%)$. On the contrary, at high Mo loading, there is no significant difference in the distribution of Co ions present on pure $\mathrm{SiO}_{2}$ and $\mathrm{Pdop} / \mathrm{SiO}_{2}$.

Table 3

Metal distribution for cobalt and molybdenum species present at the surface of sulfided CoMoS supported on $\mathrm{SiO}_{2}$ and $6.4 \mathrm{wt} \% \mathrm{Pdop} / \mathrm{SiO}_{2}$ obtained from XPS analysis.

\begin{tabular}{|c|c|c|c|c|c|c|c|c|c|c|}
\hline \multirow[b]{2}{*}{ Catalyst } & \multirow{2}{*}{$\begin{array}{c}\begin{array}{c}\text { Atomic } \\
\text { Ratio }\end{array} \\
\text { Co:Mo } \\
\text { Slabs } \\
\end{array}$} & \multicolumn{3}{|c|}{$\begin{array}{l}\text { Mo species } \\
\text { (\% relative) }\end{array}$} & \multicolumn{3}{|c|}{$\begin{array}{l}\text { Co species } \\
\text { (\% relative) }\end{array}$} & \multicolumn{2}{|c|}{$\begin{array}{l}\text { S species } \\
\text { (\% relative) }\end{array}$} & \multirow{2}{*}{$\begin{array}{c}\begin{array}{c}\text { Atomic } \\
\text { ratio }\end{array} \\
\text { Co:Mo } \\
\text { total }\end{array}$} \\
\hline & & $\mathrm{MoS}_{2}$ & $\mathrm{MoO}_{\mathrm{x}} \mathrm{S}_{\mathrm{y}}$ & $\mathrm{Mo}^{+\mathrm{VI}}$ & $\mathrm{Co}_{9} \mathrm{~S}_{8}$ & $\mathrm{CoO}$ & CoMos & $S_{\text {Sulf }}$ & $S_{\text {ox }}$ & \\
\hline $\begin{array}{c}10 \% \mathrm{CoMoS} \\
\mathrm{SiO}_{2}\end{array}$ & 0.17 & 77 & 13 & 10 & 52 & 25 & 23 & 84 & 16 & 0.58 \\
\hline $\begin{array}{c}\text { 10\%CoMoS/ } \\
\mathrm{Pdop} \mathrm{SiO}_{2}\end{array}$ & 0.28 & 78 & 13 & 9 & 38 & 26 & 36 & 86 & 14 & 0.61 \\
\hline $\begin{array}{c}20 \% \mathrm{CoMoS} / \\
\mathrm{SiO}_{2}\end{array}$ & 0.34 & 78 & 13 & 9 & 24 & 31 & 45 & 88 & 12 & 0.59 \\
\hline $\begin{array}{c}20 \% \text { CoMoS/ } \\
\text { Pdop/SiO }\end{array}$ & 0.29 & 78 & 13 & 9 & 25 & 29 & 46 & 87 & 13 & 0.49 \\
\hline
\end{tabular}

\subsection{Catalytic tests on $\mathrm{SiO}_{2}$ - and $\mathrm{Pdop} / \mathrm{SiO}_{2}$-supported catalysts.}

\subsubsection{Hydrogenation of toluene}

At both low and high Mo loadings, the conversion of toluene using the $\mathrm{Pdop} / \mathrm{SiO}_{2}$ support increases by $30-40 \%$ when compared with the catalysts supported on pure $\mathrm{SiO}_{2}(\mathrm{Fig}$. 9). Consequently, the corresponding first order rate constants normalized per mole of Mo loaded in 
the reactor $(k)$ increased by a factor of about 1.5 to nearly 2 showing a large increase of the intrinsic activity. At high Mo loading, $k$ ' decreases on both $\mathrm{Pdop} / \mathrm{SiO}_{2}$ and pure $\mathrm{SiO}_{2}$, indicating that the active catalytic sites does not increase proportionally with the Mo content.
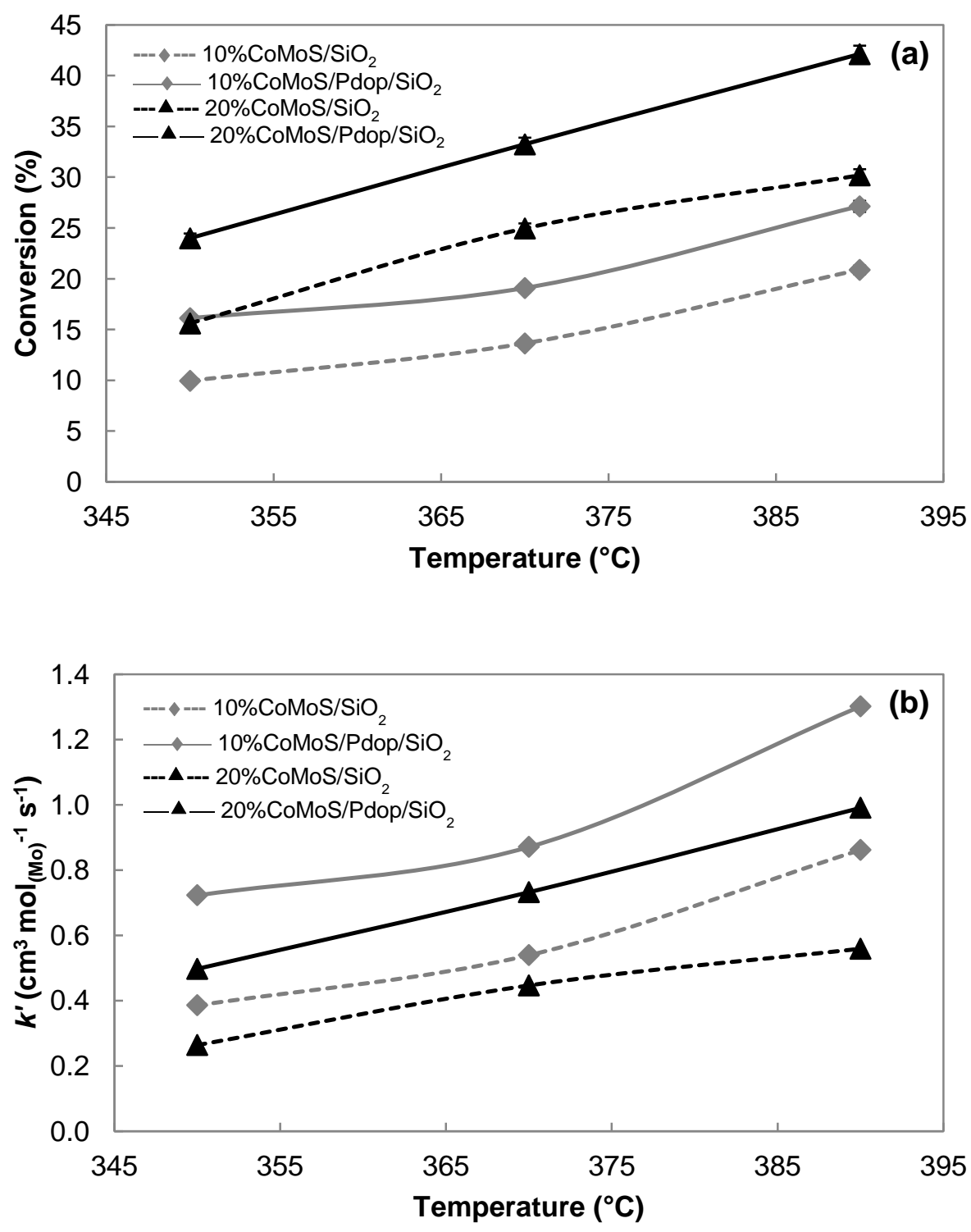

Fig. 9. (a) Conversion and (b) first-order rate constants $(k)$ normalized by the moles of $M o$ in the catalysts for toluene hydrogenation at 350,370 and $390^{\circ} \mathrm{C}$ using 10 and $20 \mathrm{wt} \%$ of targeted $\mathrm{MoO}_{3}$ loading on $\mathrm{Pdop} / \mathrm{SiO}_{2}$ and $\mathrm{SiO}_{2}$.

\subsubsection{HDS of 3-methylthiophene (3-MT) versus HYD of 2,3-dimethyl-2-butene (2,3-DM2B)}

Selective removal of sulfur from (benzo)thiophene derivatives while avoiding the hydrogenation of olefins (HYD), is a key requirement in the selective FCC gasoline hydrotreating. The competitive conversion of 3-MT (HDS) versus HYD of 2,3-DM2B is used as a test reaction to evaluate the different CoMoS catalysts. At both low and high Mo loading, CoMoS 
catalysts supported on $13.8 \mathrm{wt} \% \mathrm{Pdop} / \mathrm{SiO}_{2}$ showed an increase in the conversion by a factor of about two for both HDS and HYD reactions compared to their counterparts supported on pure $\mathrm{SiO}_{2}$. For both low and high Mo loadings, the first order rate constants ( $k$ ', Table 4) for 3-MT conversion using CoMoS supported on $\mathrm{Pdop} / \mathrm{SiO}_{2}$ increased by a factor of about 2 when compared to that of CoMoS on pure $\mathrm{SiO}_{2}$. The $k$ ' for HYD of 2,3-DM2B increased by a factor of about 2.5 to 3 (Table 4). Selectivity graph for the conversions of 3-MT and HYD of 2,3-DM2B is presented in Fig. 10. The selectivity for 3-MT conversion is slightly decreased at low Mo loading, whereas, at high Mo loading the selectivity is intact. That means Pdop allows to increase the activity without any significant loss of selectivity which is quite unusual.
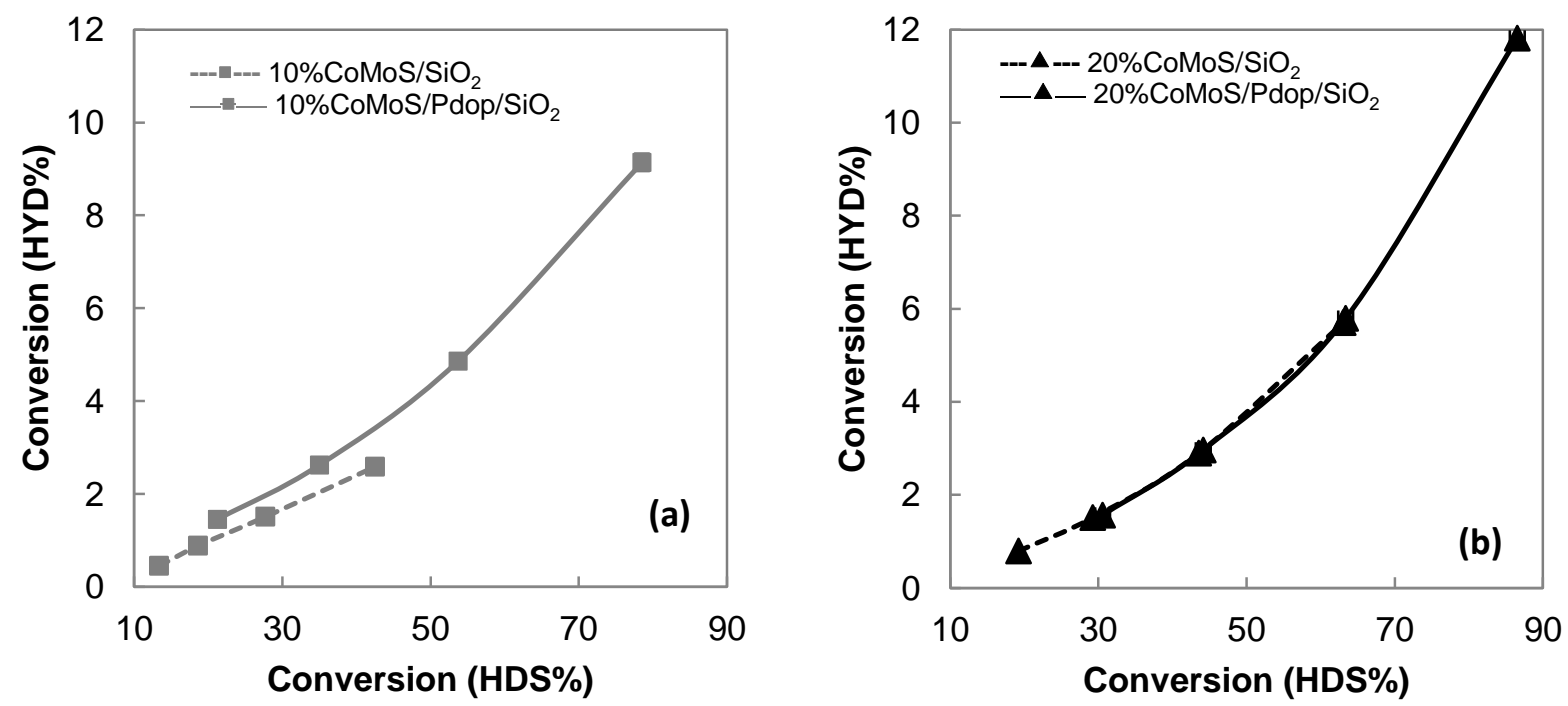

Fig. 10. Conversion in HYD of 2,3-dimethyl-2-butene versus conversion of 3-methylthiophene at 190, 200, 210 and $220^{\circ} \mathrm{C}$ using a) $10 \mathrm{wt} \%$ and b) $20 \mathrm{wt} \%$ of targeted loading on $\mathrm{Pdop} / \mathrm{SiO}_{2}$ and $\mathrm{SiO}_{2}$.

\section{Table 4}

First order rate constants normalized by moles of Mo in the catalyst ( $k$ ) for HDS of 3-MT and 2,3-DM2B for the CoMoS catalysts supported on $\mathrm{SiO}_{2}$ and $\mathrm{Pdop} / \mathrm{SiO}_{2}$.

\begin{tabular}{|c|c|c|c|c|c|c|c|c|}
\hline \multirow{2}{*}{ Catalysts } & \multicolumn{4}{|c|}{$\begin{array}{c}k^{\prime}(\mathrm{HDS}) \\
\left(\mathrm{cm}^{3} \mathrm{~mol}_{(\mathrm{Mo})}{ }^{-1} \mathrm{~h}^{-1}\right)\end{array}$} & \multicolumn{4}{|c|}{$\begin{array}{c}k^{\prime}(\mathrm{HYD}) \\
\left(\mathrm{cm}^{3} \mathrm{~mol}_{(\mathrm{Mo})}^{-1} \mathrm{~h}^{-1}\right)\end{array}$} \\
\hline & $\begin{array}{l}190 \\
{ }^{\circ} \mathrm{C}\end{array}$ & $\begin{array}{l}200 \\
{ }^{\circ} \mathrm{C}\end{array}$ & $\begin{array}{l}210 \\
{ }^{\circ} \mathrm{C}\end{array}$ & $\begin{array}{c}220 \\
{ }^{\circ} \mathrm{C}\end{array}$ & $\begin{array}{l}190 \\
{ }^{\circ} \mathrm{C}\end{array}$ & $\begin{array}{l}200 \\
{ }^{\circ} \mathrm{C}\end{array}$ & $\begin{array}{l}210 \\
{ }^{\circ} \mathrm{C}\end{array}$ & $\begin{array}{l}220 \\
{ }^{\circ} \mathrm{C}\end{array}$ \\
\hline $10 \% \mathrm{CoMoS} / \mathrm{SiO}_{2}$ & 2.91 & 4.18 & 6.59 & 11.24 & 0.09 & 0.18 & 0.31 & 0.53 \\
\hline 10\%CoMoS/Pdop/SiO 2 & 4.31 & 7.79 & 13.92 & 27.80 & 0.26 & 0.48 & 0.90 & 1.73 \\
\hline $20 \% \mathrm{CoMoS} / \mathrm{SiO}_{2}$ & 1.49 & 2.42 & 4.00 & 6.96 & 0.06 & 0.11 & 0.21 & 0.41 \\
\hline $20 \% \mathrm{CoMoS} / \mathrm{Pdop} / \mathrm{SiO}_{2}$ & 2.90 & 4.64 & 7.99 & 15.95 & 0.13 & 0.24 & 0.47 & 1.00 \\
\hline
\end{tabular}




\subsection{CoMo supported on Pdop coated titania and its catalytic activity}

$\mathrm{Pdop} / \mathrm{TiO}_{2}$ was prepared by impregnating the carrier with $6.4 \mathrm{wt} \%$ of dopaminehydrochloride. The FTIR spectrum showed that the peak around $3600 \mathrm{~cm}^{-1}$ corresponding to stretching vibrations of the hydroxyl groups on $\mathrm{TiO}_{2}$ support [33] considerably decreased upon Pdop coating (Fig. S8), evidencing the modification of titania surface by Pdop. The results from thermogravimetric analysis showed partial polymerization of dopamine (Fig. S9), similar to that on $\mathrm{Pdop} / \mathrm{SiO}_{2}$ (Fig. S1). In addition, $\mathrm{Pdop} / \mathrm{TiO}_{2}$ appeared in orange color, in contrast to the black or dark brown color (typical color for Pdop) for $\mathrm{Pdop} / \mathrm{Al}_{2} \mathrm{O}_{3}$ and $\mathrm{Pdop} / \mathrm{SiO}_{2}$. It is well documented in literature that titania binds strongly with the catechol groups of dopamine in a bidentate geometry [34]. The solid-state UV analysis of the $\mathrm{Pdop} / \mathrm{TiO}_{2}$ support showed the ligand-to-metal charge transfer complex formation between $\mathrm{TiO}_{2}$ and catechol groups [35] extended the absorption into the visible light region as apparently indicated by the color change (Fig. S10).

As previously described, the $\mathrm{Pdop} / \mathrm{TiO}_{2}$ and bare $\mathrm{TiO}_{2}$ supports were impregnated with Mo and Co precursors (10 wt\% of targeted $\mathrm{MoO}_{3}$ loading) using ethanol as the solvent. TEM analysis (Figs. S11-12 and Table S2) revealed that the dopamine-coating increases the mean slab length of $\mathrm{MoS}_{2}$ nanocrystallites (from $3.1 \mathrm{~nm}$ on bare $\mathrm{TiO}_{2}$ to $3.7 \mathrm{~nm}$ on $\mathrm{Pdop} / \mathrm{TiO}_{2}$ ). The stacking of $\mathrm{MoS}_{2}$ slabs ( 1.6) was similar on both supports. It can be concluded from TEM results that the number of exposed edge atoms of $\mathrm{MoS}_{2}$ decreases with the addition of Pdop. XPS study (Table S3) showed that the degree of sulfidation of $\mathrm{Mo}$ ions on $\mathrm{Pdop} / \mathrm{TiO}_{2}(77 \%)$ is slightly better when compared that on bare $\mathrm{TiO}_{2}(68 \%)$. However, the percentage of catalytically inactive $\mathrm{Co}_{9} \mathrm{~S}_{8}$ phase is somewhat higher on $\mathrm{Pdop} / \mathrm{TiO}_{2}(11 \%)$ when compared to pure $\mathrm{TiO}_{2}(4 \%)$.

The conversion of toluene using CoMoS catalysts with Pdop was lower than the catalysts on pure $\mathrm{TiO}_{2}$ and, the corresponding first order rate constants normalized per mole of Mo loaded in the reactor $(k)$ were reduced by $20-30 \%$ (Fig. 11 ).

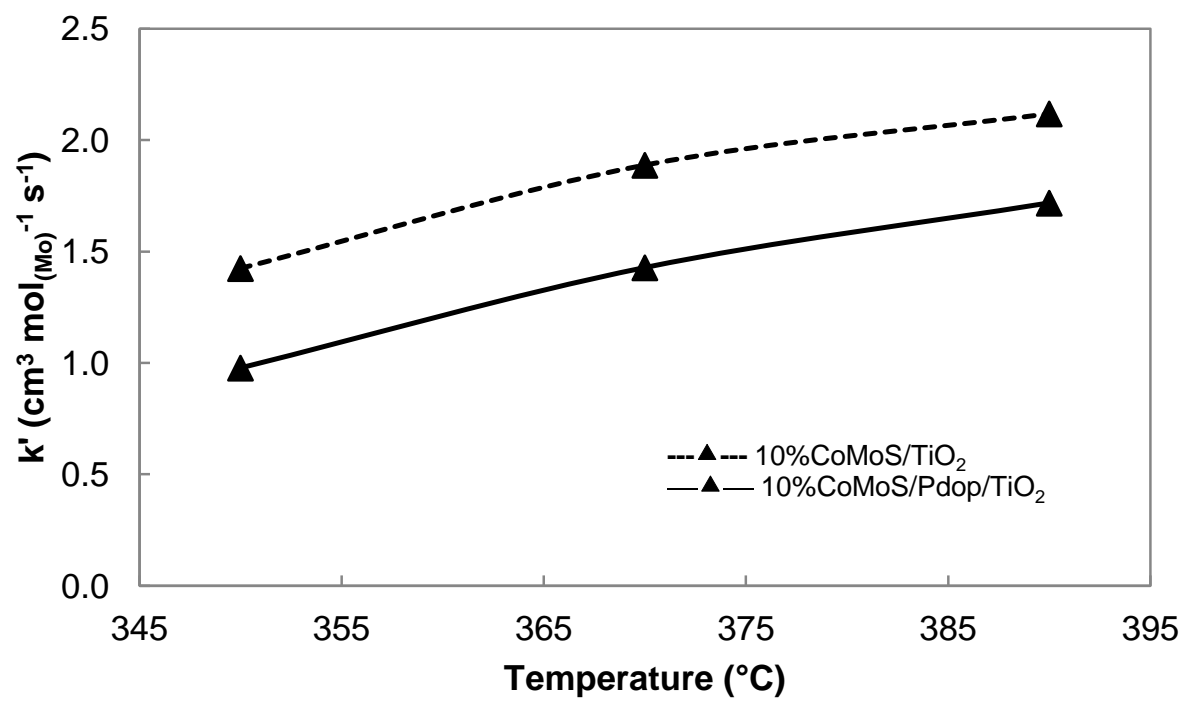

Fig. 11. First-order rate constants $\left(k^{\prime}\right)$ normalized by the moles of Mo in the catalysts for toluene hydrogenation at 350,370 and $390^{\circ} \mathrm{C}$ using $10 \mathrm{wt} \%$ of targeted loading of $\mathrm{MoO}_{3}$. 


\subsection{Discussion}

\subsubsection{Coating of oxide carriers by dopamine: $\mathrm{Al}_{2} \mathrm{O}_{3}$ vs. $\mathrm{SiO}_{2}$ vs. $\mathrm{TiO}_{2}$}

Dopamine polymerizes easily on $\mathrm{Al}_{2} \mathrm{O}_{3}$, since the point of zero charge (PZC) of this amphoteric support is about $\mathrm{pH} 9 . \mathrm{Al}_{2} \mathrm{O}_{3}$ surface hydroxyls act as basic groups when contacting with the slightly acidic dopamine solution, raising the $\mathrm{pH}$ to mild basic conditions required for dopamine polymerization. As a result, Pdop covers the surface of $\mathrm{Al}_{2} \mathrm{O}_{3}$, further preventing the interaction of metallic precursors with surface $\mathrm{OH}$ groups [18]. In the case of $\mathrm{SiO}_{2}$, dopamine is not expected to polymerize as it was observed in the case of $\mathrm{Al}_{2} \mathrm{O}_{3}$, because the $\mathrm{PZC}$ of $\mathrm{SiO}_{2}$ is about $\mathrm{pH} 3$ far from the basic conditions required for total polymerization. Nevertheless, it has been shown by FTIR that dopamine moieties cover the surface silanol groups. Further, TGA and UV-Vis measurements showed a partial polymerization, likely to occur during drying step in the presence of oxygen from air [23]. The degree of polymerization of dopamine is lower on silica than on alumina as evidenced from TGA and UV-Vis analysis (Fig. S2). A similar behavior is observed for $\mathrm{TiO}_{2}$, even though its $\mathrm{PZC}$ is in the range of $\mathrm{pH}$ 5-6.

When Mo precursors are added to Pdop coated $\mathrm{Al}_{2} \mathrm{O}_{3}$ or $\mathrm{SiO}_{2}$, the catechol groups present in Pdop form a complex with the Mo ions [30]. Consequently, Mo is distributed evenly on the Pdop coated surface of the support. However, in the case of $\mathrm{TiO}_{2}$, there is a strong bidentate complex formation between the catechol groups of dopamine and $\mathrm{Ti}^{+\mathrm{IV}}$ [34]. This strong complexation is much less pronounced for $\mathrm{Al}_{2} \mathrm{O}_{3}$ and $\mathrm{SiO}_{2}$ supports. Hence, Pdop functional groups are available to interact with metallic precursor helping the dispersion. On the other hand, on $\mathrm{TiO}_{2}$ due to strong complexation with $\mathrm{Ti}^{+\mathrm{IV}}$, these groups are no longer able to stabilize Mo precursors leading to sintering of $\mathrm{MoS}_{2}$ crystallites. Further, from FTIR spectra of $\mathrm{Al}_{2} \mathrm{O}_{3}$, $\mathrm{SiO}_{2}$, and $\mathrm{TiO}_{2}$ at similar Pdop loading (6.4 wt\%), it was observed that the contribution from catechol $(\mathrm{OH})$ groups above $3300 \mathrm{~cm}^{-1}$ is considerably lower on $\mathrm{TiO}_{2}$ when compared than on $\mathrm{Al}_{2} \mathrm{O}_{3}$ and $\mathrm{SiO}_{2}$ (Fig. S13), in agreement with the above hypothesis. Convincingly, the nature of the interaction between the support and the Pdop functional groups plays a decisive in improving the dispersion of the $\mathrm{MoS}_{2}$ crystallites.

\subsubsection{Effect of Pdop coating on catalytic activity}

CoMoS catalysts supported on $\mathrm{Pdop} / \mathrm{SiO}_{2}$ were systematically more active in the hydrogenation of toluene and FCC gasoline model molecules than the catalysts supported on bare $\mathrm{SiO}_{2}$. The higher activities of the catalysts supported on $\mathrm{Pdop} / \mathrm{SiO}_{2}$ could arise from different factors, which are discussed in the following.

In our previous study, CoMoS supported on $\mathrm{Pdop} / \mathrm{Al}_{2} \mathrm{O}_{3}$ also showed enhancement in catalytic activity mainly due to the better dispersion of $\mathrm{MoS}_{2}$ slabs and the prevention of direct detrimental metal support interaction, owing to the presence of carbon adlayer between the support and metal [18]. Comprehensively, a similar explanation holds true in the case of CoMoS/Pdop/SiO 2 . The low metal-support interactions of $\mathrm{SiO}_{2}$ favor the stacking of $\mathrm{MoS}_{2}$ sheets [36]. The Pdop coating significantly reduced the stacking (revealed by in-situ XRD and TEM measurements), at both low and high Mo loadings (Table 2). This behavior is quite unusual. Carbon-coated supports generally show higher stacking number when compared to the bare support due to the poor interaction of the carbon interface and the metal precursors [37]. With a 
Pdop coating, the stacking effect has been circumvented: thanks to the presence of Pdop functional groups, $\mathrm{MoS}_{2}$ slabs are more regularly distributed on the surface of silica support converting a poor dispersing oxide surface into a highly dispersing carbonaceous deposit. Though the degree of polymerization is lower on silica than on alumina, the catalytic activity is consistently higher on both silica and alumina, indicating polymerization is not a critical factor in improving the catalytic efficiency. We presume that the better dispersion on the support surface is the main reason for the observed increase in catalytic activity.

The presence of carbon in the sulfided CoMo on $\mathrm{Pdop} / \mathrm{SiO}_{2}$ could also lead to enhancement in catalytic activity. On Pdop coated $\mathrm{SiO}_{2}$, Mo ions complexes with catechol groups present in Pdop [30]. Upon sulfidation though the complex decomposes, but still leaves carbonaceous deposit in the catalyst (at least $40 \%$ of carbon from the initial carbon content in Pdop) even after sulfidation step, with no pore blocking effect and keeping textural properties intact. This carbon is most probably present as an adlayer on $\mathrm{SiO}_{2}$, thereby avoiding direct contact of $\mathrm{MoS}_{2}$ nanocrystallites with $\mathrm{SiO}_{2}$. Consequently, now $\mathrm{MoS}_{2}$ is most possibly present on carbon like support. CoMoS phase on carbon supports generally belongs to type-II [16,38], which is characterized by weak van der Waals' interactions between the active sulfide and the support and a high intrinsic activity.

There was no direct evidence observed for an increase of Co-promoted edge sites [39] (CoMoS from XPS) on $\mathrm{Pdop} / \mathrm{Al}_{2} \mathrm{O}_{3}$, which would contribute to the increase in catalytic inactivity. At low Mo loading, the $\mathrm{MoS}_{2}$ slab length was reduced (TEM results, Table 2) and the degree of promotion was enhanced on $\mathrm{Pdop} / \mathrm{SiO}_{2}$ leading to an increase in CoMoS (+ 57\%) sites (XPS results, Table 3) compared to pure $\mathrm{SiO}_{2}$. However, these features were not observed on $\mathrm{Pdop} / \mathrm{SiO}_{2}$ with high Mo loading. Therefore, it is not expected to be the primary reason for the increase in catalytic activity.

The poor performance of catalysts supported on $\mathrm{Pdop} / \mathrm{TiO}_{2}$ could be attributed to the following factors: (i) catechol groups on dopamine form strong bonds with $\mathrm{Ti}$ and that causes change in the electronic properties of $\mathrm{TiO}_{2}$, owing to the direct catechol-to- $\mathrm{TiO}_{2}$ charge transfer [40], (ii) as catechol groups binds to titania, the number of binding sites for Mo decreases that led to the sintering of $\mathrm{MoS}_{2}$ nanocrystallites, (iii) results from TEM showed that the $\mathrm{MoS}_{2}$ slab length strongly increases on $\mathrm{Pdop} / \mathrm{TiO}_{2}$, which eventually decreases the active phase on the edge sites of $\mathrm{MoS}_{2}$ slabs, and (iv) XPS results showed that percentage of $\mathrm{Co}_{9} \mathrm{~S}_{8}$ phase on $\mathrm{Pdop} / \mathrm{TiO}_{2}$ is higher, as a result, the number of $\mathrm{Co}$ ions decorating the edge sites of $\mathrm{MoS}_{2}$ slabs is smaller.

\section{Conclusion}

In conclusion, we have demonstrated a bio-inspired, facile method to coat $\mathrm{SiO}_{2}$ and $\mathrm{TiO}_{2}$ with Pdop. The nature of the interaction between the support and the Pdop functional groups plays a key role in the dispersion of the $\mathrm{MoS}_{2}$ crystallites. On $\mathrm{Pdop} / \mathrm{SiO}_{2}$, as there is no strong interaction between the support and Pdop, functional groups on Pdop helps in dispersing metal precursors. In-situ XRD measurements and TEM analysis confirmed that majority of $\mathrm{MoS}_{2}$ slabs are present in the catalysts as single or double slabs resulting in better repartition on $\mathrm{Pdop} / \mathrm{SiO}_{2}$ 
than on pure $\mathrm{SiO}_{2}$. Despite of the presence of carbon residues in the sulfided catalysts, textural properties were intact, indicating the homogeneous deposition on the surface of the support. The CoMoS catalyst on Pdop coating increases the first order rate constants $(k)$ for toluene hydrogenation, conversions of 3-MT, and HYD of 2,3-DM2B by a factor of about 2 than its counterpart on pure $\mathrm{SiO}_{2}$. The improved activity is attributed to the decreased aggregation of $\mathrm{MoS}_{2}$ nanocrystallites leading to increase in edge site accessibility, and to the presence of carbonaceous adlayer between the active phase and the support limiting the direct interaction of metal precursors with the support. This coating strategy was less successful on $\mathrm{TiO}_{2}$ owing to the stronger interaction of Pdop with titania decreasing its ability to disperse Mo active phase, consequently, decrease in catalytic activity. This point highlights the need for the appropriate interactions of the (oxidic carrier/Pdop/metallic precursors) system which have to be tuned in order to improve the final catalytic performances.

\section{Acknowledgements}

Anne Boffo is thanked for the technical help in the laboratory. Sylvain Carbonneaux, Mickaël Rivallan, Anne-Sophie Gay, Christèle Legens and their technical teams are acknowledged for XRF, FTIR, XRD, TEM, and XPS measurements. We are grateful for Mathieu Vidalie for his support in performing catalytic tests. We express our gratitude to Eric Puzenat for his assistance with solid state UV-VIS analysis.

\section{References}

[1] A. Stanislaus, A. Marafi, M.S. Rana, Catal. Today 153 (2010) 1-68.

[2] H. Toulhoat, P. Raybaud, Catalysis by transition metal sulphides: From molecular theory to industrial application, Editions Technip, Paris, 2013.

[3] R. Wang, G. Zhang, H. Zhao, catal. Today 149 (2010) 117-121.

[4] K. Hiroshima, T. Mochizuki, T. Honma, T. Shimizu, M. Yamada, Appl. Surf. Sci. 121-122 (1997) 433-436.

[5] L. Coulier, V. de Beer, J. van Veen, J.W. Niemantsverdriet, Top. Catal. 13 (2000) 99-108.

[6] Y. Ohta, T. Shimizu, T. Honma, M. Yamada, Stud. Surf. Sci. Catal. 127 (1999) 161-168.

[7] T.S. Nguyen, S. Loridant, L. Chantal, T. Cholley, C. Geantet, Appl. Catal. B: Environ. 107 (2011) 59-67.

[8] D. Nicosia, R. Prins, J. Catal. 229 (2005) 424-438.

[9] M. Breysse, P. Afanasiev, C. Geantet, M. Vrinat, Catal. Today 86 (2003) 5-16.

[10] C. Roukoss, D. Laurenti, E. Devers, K. Marchand, L. Massin, M. Vrinat, Comptes Rendus Chimie 12 (2009) 683-691.

[11] Y. Sakashita, Surf. Sci. 489 (2001) 45-58.

[12] A. Nogueira, R. Znaiguia, D. Uzio, P. Afanasiev, G. Berhault, Appl. Catal. A: Gen. 429-430 (2012) 92-105.

[13] G. Pérot, Catal. Today 86 (2003) 111-128.

[14] V. La Parola, G. Deganello, C. Tewell, A. Venezia, Appl. Catal. A: Gen. 235 (2002) 171180. 
[15] G. Berhault, M. Lacroix, M. Breysse, F. Maugé, J.-C. Lavalley, H. Nie, L. Qu, J. Catal. 178 (1998) 555-565.

[16] S. M. A. M. Bouwens, F. B. M. Vanzon, M.P. Vandijk, A.M. Vanderkraan, V. H. J. Debeer, J. A. R. Vanveen, D.C. Koningsberger, J. Catal. 146 (1994) 375-393.

[17] J. Ramirez, S. Fuentes, G. Díaz, M. Vrinat, M. Breysse, M. Lacroix, Appl. Catal. 52 (1989) 211-223.

[18] R. Munirathinam, D. Laurenti, G.D. Pirngruber, D. Uzio, ChemistrySelect 2 (2017) 23732382.

[19] J. Wu, L. Zhang, Y. Wang, Y. Long, H. Gao, X. Zhang, N. Zhao, Y. Cai, J. Xu, Langmuir 27 (2011) 13684-13691.

[20] H. Lee, S.M. Dellatore, W.M. Miller, P.B. Messersmith, Science (New York, N.Y.) 318 (2007) 426-430.

[21] Y. Liu, K. Ai, L. Lu, Chem. Rev. 114 (2014) 5057-5115.

[22] G. Magendie, B. Guichard, D. Espinat, Catal. Today 258 (2015) 304-318.

[23] W. Zheng, H. Fan, Le Wang, Z. Jin, Langmuir 31 (2015) 11671-11677.

[24] B.A. Morrow, A.J. McFarlan, J. Non-Cryst. Solids 120 (1990) 61-71.

[25] M. Müller, B. Kessler, Langmuir 27 (2011) 12499-12505.

[26] X. Du, L. Li, J. Li, C. Yang, N. Frenkel, A. Welle, S. Heissler, A. Nefedov, M. Grunze, P.A. Levkin, Adv. Mater. 26 (2014) 8029-8033.

[27] Traditionally volume of adsorbed N2 is normalized by the mass of the materials, but in our case we have normalized by the volume of the material. Because, when reasoning per volume instead of per mass, the gain in the mass of the material upon coating Pdop is neutralized, thereby allowing us to see the precise difference between the bare support and Pdop coated support.

[28] M. Zheng, Y. Shu, J. Sun, T. Zhang, Catal. Lett. 121 (2008) 90-96.

[29] J. Vissers, F. Mercx, S. Bouwens, V. de Beer, R. Prins, J. Catal. 114 (1988) 291-302.

[30] C. Zhao, J. Kong, L. Yang, X. Yao, S.L. Phua, X. Lu, Chem. Commun. 50 (2014) $9672-$ 9675.

[31] K.S. Liang, R.R. Chianelli, F.Z. Chien, S.C. Moss, J. Non-Cryst. Solids 79 (1986) 251-273.

[32] B. Radisavljevic, A. Radenovic, J. Brivio, V. Giacometti, A. Kis, Nat. Nanotechnol. 6 (2011) 147-150.

[33] D. J. C. Yates, J. Phys. Chem. 65 (1961) 746-753.

[34] K. Syres, A. Thomas, F. Bondino, M. Malvestuto, M. Grätzel, Langmuir 26 (2010) 1454814555.

[35] S.J. Hurst, H.C. Fry, D.J. Gosztola, T. Rajh, J. Phys. Chem. C 115 (2011) 620-630.

[36] P. Faye, E. Payen, D. Bougeard, Stud. Surf. Sci. Catal. 106 (1997) 281-292.

[37] P.A. Nikulshin, V.A. Salnikov, A.V. Mozhaev, P.P. Minaev, V.M. Kogan, A.A. Pimerzin, J. Catal. 309 (2014) 386-396.

[38] A.I. Dugulan, J. van Veen, E. Hensen, Appl. Catal. B: Environ. 142-143 (2013) 178-186.

[39] M. Daage, R.R. Chianelli, J. Catal. 149 (1994) 414-427.

[40] P. Persson, R. Bergström, S. Lunell, J. Phys. Chem. B 104 (2000) 10348-10351. 
Supplementary Material
Click here to download Supplementary Material: SI-Applied Catal. A_latest version.docx

Supplementary Material
Click here to download Supplementary Material: SI-Applied Catal. A_latest version.docx

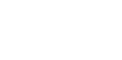

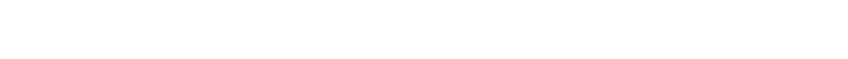

-

(1) 